\section{VIEJOS Y NUEVOS DEBATES: JUVENTUD Y ACCIÓN SOCIOPOLÍTICA}

\author{
Imanol Zubero \\ Universidad del País Vasco \\ ORCID iD: https://orcid.org/0000-0001-5699-337X \\ imanol.zubero@ehu.eus
}

Cómo citar este artículo/Citation: Zubero, I. (2018). Viejos y nuevos debates: juventud y acción sociopolítica. Arbor, 194 (787): a429. https://doi.org/10.3989/arbor.2018.787n1002

Recibido: 31 enero 2017. Aceptado: 13 noviembre 2017

RESUMEN: En este artículo analizamos tres cuestiones centrales que se plantearon en 1968 y se siguen planteando en la actualidad: el quién (el sujeto), el qué (los contenidos) y el cómo (los medios) de la acción sociopolítica transformadora. Cuestiones que no nacen en aquel momento, pero que sí quedaron formuladas en unos términos que han llegado hasta la actualidad.

PALABRAS CLAVE: 1968; izquierda; juventud; clase obrera; organización.

\section{OLD AND NEW DEBATES: YOUTH AND SOCIO-POLITICAL ACTION}

Copyright: (C) 2018 CSIC. Este es un artículo de acceso abierto distribuido bajo los términos de la licencia de uso y distribución Creative Commons Reconocimiento 4.0 Internacional (CC BY 4.0).

ABSTRACT: In this article we analyze three central issues raised in 1968 and still under consideration today: the who (the subject), the which (the contents) and the how (the means) for the transformative socio-political action. Issues not born in that time, but raised then in terms that have survived to the present day.

KEYWORDS: 1968; left wing; youth; working class; organization. 
"iCuál sería mi felicidad viendo en el poder a una izquierda realista y responsable y en las calles, empresas, ciudades y escuelas una izquierda apasionada y creadora!; dos izquierdas que unas veces se enfrentarían y otras se apoyarían, pero que siempre serían conscientes de estar unidas para lo mejor y para lo peor, bajo la amenazadora mirada de las fuerzas de derecha y de la vieja clase dirigente" (Touraine, 1977, p. 48).

"Desde 1968 han entrado en nuestra vida temas y modos de acción que ya no se perderán", escribe Touraine (1977, p. 36) en una de sus Cartas a una estudiante. Tres décadas más tarde, los editores españoles de un libro sobre 1968, intelectuales militantes enmarcados en el espacio de la izquierda alternativa, lo reivindicaban como imprescindible "capital de conocimiento y experiencias" para quienes hoy aspiran a transformar la realidad (Garí, Pastor y Romero, 2008 , p. 16). Nada resulta más sencillo que construir un relato que conecte the Long Sixties (Strain, 2016) con la realidad sociopolítica actual.

En relación a la temática de este artículo, hay acuerdo en señalar que en los sesenta -aunque no tanto en el mayo francés (Fernández Buey, 2009, pp. 41-42 y pp. 90-92) - está el origen de movimientos sociales tan importantes como el feminista (Clifford, Gildea y Warring, 2013; Evans, 2015; Gitlin, 1987, pp. 362-376), el pacifista (Gallant, 2009), el ecologista (Cohn-Bendit, 2010, p. 25; Rome, 2003) y el internacionalista (hoy diríamos altermundialista) (Arrighi, Hopkins y Wallerstein, 1999; Elbaum, 2002). También se ha dicho que las nuevas teorías críticas que acompañan o inspiran las principales luchas sociales de la actualidad se han desarrollado "en el marco de coordenadas políticas heredadas de las décadas de 1960 y 1970", por lo que recogen y continúan algunos de los principales debates surgidos en aquella época, como los relativos a la naturaleza de los sujetos de la emancipación o a la consideración del poder; de ahí que pueda sostenerse que "en el momento actual continuamos evolucionando dentro de la secuencia histórica abierta entonces" (Keucheyan, 2013, p. 104).

Otra cosa es acordar cuáles son esos temas y modos de acción que hoy perduran, y evitar la tentación de construir causalidades o conexiones ex post que expliquen (o resuelvan) ciertos problemas, teóricos o prácticos, relacionados con la participación sociopolítica; especialmente aquí y ahora, por la influencia que sobre nuestro análisis del acontecimiento de mayo puede tener ese otro acontecimiento, ocurrido también en mayo, que es el 15-M de 2011, entre los que resulta inevitable establecer comparaciones (Blanco, 2014; Gil Villa, 2014; Gómez Pin et al., 2012; La ParraPérez, 2014; Ruiz Fernández, 2016; Sorman, 2011, 23 de octubre; Subirats, 2011, 22 de octubre; Townson, 2011, 6 de junio). Intentaremos evitar la tentación de las inferencias causales retrospectivas.
Escribe Coutrot (2012, p. 119) que "Ios años 19681970 vieron cómo se activaba de nuevo una división casi tan antigua como el movimiento obrero entre una "primera izquierda» intervencionista, polarizada en torno a la cuestión de la toma del poder del Estado, y una "segunda izquierda", atenta a las transformaciones moleculares del tejido social y a las iniciativas autónomas de la sociedad civil". Partiendo de esta división, que opera con fuerza en la actualidad, en esta breve reflexión nos fijaremos en tres cuestiones centrales en los debates de entonces y de ahora sobre la acción social: el quién, el qué y el cómo (los medios) de esta acción.

\section{¿QUIÉN? LA CUESTIÓN DEL(OS) SUJETO(S)}

¿Fue mayo del 68 una rebelión juvenil? Dejamos a un lado el debate sobre el sustantivo rebelión para centrarnos en el adjetivo juvenil. El imaginario social del 68, fijado por una iconografía que privilegia ciertos lugares (universidades parisinas), actores (jóvenes) y reivindicaciones (cierre de la Sorbona, barricadas del Barrio Latino), parece no dejar lugar a la duda: se trataría de un movimiento eminentemente juvenil y específicamente universitario (Chollet, 2007; Delporte, 2007; Leblanc, 2009). Predomina el marco analítico centrado en las categorías juventud o universidad, sobre todo en los diagnósticos más cercanos al momento temporal en que ocurrieron los hechos (Feuer, 1971; Hampden-Turner, 1978; Hermann, 1968; Luce, 1966; Roszak, 1970; Sauvy, 1971; Scott y Lyman, 1970). Hijos de la opulencia, consumidores saciados, educados en saberes no instrumentales; también nuevos bárbaros. Ajenos, en cualquier caso, a la cultura dominante, a la de sus progenitores y sus educadores: "generación escéptica" o "generación sin padres" (Kahl, 2008, p. 71 y p. 78). Incluso hay quien aborda los acontecimientos de mayo con el trasfondo de una "ola de violencia adolescente y brutalidad" que, iniciada a mediados de los cincuenta, sorprendió a la mayoría de las sociedades industriales avanzadas (Gretton, 1969, p. 15). Los protagonistas mismos parecen identificarse antes como jóvenes que como pertenecientes a cualquier otra categoría social, dotando a esa característica, en principio puramente cronológica, de una inmensa e indubitada potencialidad transformadora. Así, el Llamamiento de la Sorbona, aprobado los días 13 y 14 de junio de 1968, formula en su tesis 15: "Basémonos en nuestra juventud, en nuestra "inmadurez», en nuestra falta de responsabilidad para conseguir que todo el mundo alcance una visión clara de las cosas y pueda ser verdaderamente adulto, maduro y responsable" (VV. AA., 1976, p. 329).

Kristin Ross rechaza las interpretaciones del 68 como una revuelta juvenil, necesariamente transitoria. Frente a este reduccionismo "sociobiológico", sostiene que "mayo reunió grupos socialmente he- 
terogéneos e individuos cuya convergencia erosionó las particularidades, entre ellas las de clase y edad; consiguió que se materializaran alianzas imprevisibles entre distintos sectores sociales" (Ross, 2008, p. 390 y pp. 392-393). Hubo huelgas obreras, es cierto, las más importantes de la historia de Francia (Astarian, 2008; Pudal y Retière, 2008). También nació en 1968 la Conféderation Paysanne en la región de Larzac, movimiento agrícola igualitario y antiproductivista que supone una de las más destacadas "vidas posteriores" de mayo (Martin, 2014; Ross, 2008, p. 36). Pero todo esto quedó oscurecido por "el "maelstrom» estudiantil" (Morin, 2009, p. 9), que todo lo inundó.

Sin embargo, hay que matizar que apenas ningún analista -salvo alguno de muy primera hora, carente de la necesaria perspectiva, o alguno de muy última hora, cargado de pensée anti 68 (Audier, 2008)- reduce mayo a una mera cuestión juvenil. Aun partiendo de "la miseria del medio estudiantil", prácticamente todos los análisis que destacan el papel de la juventud universitaria señalan también, de una forma o de otra, que "Ios estudiantes están contemplando, más allá de la universidad, la tierra baldía de la cultura, el comercio y la política capitalista, para no mencionar una política exterior cuyo salvajismo avergonzaría a una jungla, y están espantados" (Hampden-Turner, 1978, p. 435; también: GilcherHotey, 2008, p. 111; Nieto, 1971, pp. 79-84 y p. 149; Touraine, 1968, pp. 235-273).

Fueron personas jóvenes las protagonistas, pero menos por su condición biográfica que por su experiencia generacional. Remitiéndonos a Mannheim, habría que destacar aquí no tanto la influencia de la edad como la de la contemporaneidad: los sesenta constituyeron una época en la que las viejas "entelequias" resultaron sacudidas por una oleada de cambios de tal magnitud que, afectando especialmente a las personas más jóvenes, dio lugar al "fenómeno de las unidades generacionales que se yerguen alimentadas por entelequias completamente nuevas" (Mannheim, 1993, p. 229). Si, como señala Joseph Roth (2004, p. 159), "ninguna patria da a sus hijos tantos rasgos específicos y comunes como una época a los suyos", en los sesenta se produjo un profundo cambio cultural (Inglehart, 1971; Inglehart, 1977) que, asociado a un no menos profundo cambio en los fundamentos tecnológicos y económicos de las sociedades industriales avanzadas (Bell, 1976; Touraine, 1973), generó un "espacio de tiempo" que posibilitó dos de las condiciones que Bensaïd y Weber (1968, p. 166) consideran necesarias para que se dé una situación revolucionaria: "que los de arriba no puedan ya gobernar como antes" y "que los de abajo ya no quieran vivir como antes".
Desde esta perspectiva, coincidimos con Ross (2008, p. 24) cuando sostiene que mayo del 68 tuvo menos que ver con el particular grupo social que lo protagonizó (los "estudiantes" o los "jóvenes") que con "el abandono de las determinaciones sociales, con desplazamientos que sacaron a la gente de su ubicación en la sociedad". Esta desubicación generalizada permitió que el individuo emergiera de entre todas las constricciones sociales que caracterizaban la sociedad francesa de aquel tiempo. "Cualquier otro que no sea yo es para mí un agente de represión": este lema es para Finkielkraut (2001, p. 137) la expresión de un individualismo radical que, sin embargo, no hacía sino descubrir y exaltar "los principios distintivos de la propia sociedad que creían combatir". Es esta una interpretación de los movimientos de los sesenta más adecuada al caso de Berkeley que al de Nanterre, pero que se ha convertido en dominante: los sesenta como apoteosis de la individualidad -"el acontecimiento reducido a la exhibición de una herida narcisista" (Bensaïd, 1998)-y, por ello, fácilmente reintegrables al sistema (Boltanski y Chiapello, 2002; Harvey, 2005; de Miguel, 1979; Premat, 2009; Sedlmaier, Sedlmaier y Malinowski, 2011; Sorman, 2011, 23 de octubre; Vallespín, 2009).

Castoriadis (2006, pp. 28-29) cuestiona estas lecturas en términos de preparación (o aceleración) del individualismo cuando, en su opinión, 1968 fue una reacción contra un proceso de "privatización" de las sociedades occidentales iniciado en los cincuenta y reforzado tras el interludio de mayo. Recuerda Castoriadis (1998, p. 30) "aquellas semanas de confraternización y de solidaridad activa, cuando uno podía dirigir la palabra a cualquiera en la calle sin temer ser tomado por loco". Parlez à vos voisins!: este estallido de la comunicación, esta "enorme conversación en la que todo el mundo interviene" (Sander, 2008, p. 90) es destacada por muchos protagonistas y testigos (Blanchard, 2007; Fuentes, 2005, pp. 25-26; Gallant, 2008, p. 90; Glucksmann y Glucksmann, 2008, p. 98; Rossanda, 2008, p. 403; Statera, 1977, p. 238). Incluso escépticos como Finkielkraut confiesan: "viví plenamente aquel momento de gracia, aquella interrupción sabática de la vida corriente en que la gente había dejado de cruzarse con otros, sin más, y, por el contrario, se escuchaban, se disputaban el uso de la palabra. Con la participación de todos y cada uno y ante el estupor general, el hormiguero se había convertido en ágora" (Finkielkraut, 2014, p. 12 y p. 69). Frente a la interpretación individualista de mayo, Cohn-Bendit (Today the big political game is 'bashing the 1960s', p. 64) sostiene que "la autodeterminación de 1968 fue colectiva". Individualista, sí, pero no en el sentido liberal del término: 
En y mediante el movimiento de mayo ha tenido lugar una formidable resocialización, aun cuando ésta ha mostrado ser pasajera. La gente no buscaba sentir el calor y el olor de los otros -ni solamente «estar juntos». [...] Buscaban la verdad, la justicia, la libertad, la comunidad [...]. Si se quiere comprender dónde estaba el «individualismo» en mayo del 68, piénsese entonces en lo que, tras la modificación de los acuerdos de Grenelle, selló el desmoronamiento del movimiento: el reabastecimiento de los surtidores de gasolina. El orden quedó definitivamente restablecido cuando el francés medio volvió a poder dirigirse, en su coche, con su familia, hacia su segunda residencia o su lugar de pícnic (Castoriadis, 1998, pp. 30-31).

Como la juventud, también la clase obrera se vio crecientemente desubicada cuando las determinaciones sociales que la definían como categoría social saltaban por los aires a medida que las sociedades capitalistas transitaban hacia el post-industrialismo y el post-materialismo. Mayo de 1968 supone la quiebra definitiva del proletariado como sujeto histórico privilegiado, en realidad único, y la progresiva aparición de una miríada de nuevos sujetos (o nuevas subjetividades) sociales. Esta quiebra provocó algunas de las tensiones más importantes y duraderas en el seno de los movimientos de mayo: fue como si los activistas se negaran a reconocer su labor de "destrucción creativa" de unas viejas estructuras, espacios y formas de lucha, y su sustitución por otras nuevas. Al tiempo que los estudiantes buscaban la aprobación y el apoyo de los trabajadores, "mostraban por su movimiento mismo, que las reivindicaciones más radicales, más importantes, ya no eran llevadas adelante por la clase obrera, sino por ellos y otras capas que se movilizaban en ese momento" (Castoriadis, 2006, p. 214).

El mayo francés, a diferencia de lo que ocurría en los campus norteamericanos, estaba influido por un recuerdo nostálgico del movimiento obrero (Cohn-Bendit, 2010, p. 18); de ahí que soñara con el momento en que "las cóleras de las diferentes categorías sociales" Ilegaran a unirse, con resultados explosivos (Glucksmann, 1976, p. 30). Las y los estudiantes seguían pensando que solo la clase obrera tenía la capacidad y la voluntad de hacer la revolución (Castoriadis, 2006, p. 214; Nieto, 1971, p. 151), y se empeñaron en lograr el reconocimiento de esta mediante acciones caracterizadas, a veces, por "rasgos masoquistas de humildad" (Nieto, 1971, p. 111), como la marcha estudiantil que el 16 de mayo parte desde la Sorbona hacia la factoría de Renault-Billancourt con una pancarta que dice: "Los trabajadores tomarán de las frágiles manos de los estudiantes la antorcha de la rebelión contra el régimen antipopular de desempleo y de miseria" (Bensaïd y Weber,
1968 , p. 156). Pero pronto se enfrentaron a la realidad de una clase trabajadora férreamente controlada por el PC y la CGT, que desde el primer momento intentaron bloquear la agitación social mediante el juego parlamentario, y que seguía viendo a los estudiantes no como iguales sino como sus futuros jefes (Duverger, 2008, pp. 21-22; Gallant, 2008, p. 32; Nieto, 1971, pp. 111-112). De ahí la temprana ruptura superadora de mayo con el PC: "Con el PCF no existen divergencias políticas, ni siquiera una exigencia de mayor democracia. [...] Hemos pasado el umbral sin retorno y apuntamos hacia otro objetivo social" (Cohn-Bendit, 1976, p. 119). Solo en Italia se llegó a realizar "lo que mayo dejó entrever, la gota a punto de colmar el vaso obrero", de manera que "las luchas abandonaron con frecuencia el terreno de la fábrica para llegar hasta la ciudad, hasta la organización global de la sociedad" (Cohn-Bendit, 1976, pp. 135137). Sin embargo, también aquí se produjo la ruptura con el PC: "No entraban en polémica con el PCI [...]. El enemigo era el «sistema», apuntaban alto. [...] El problema no era que el $\mathrm{PCl}$ se sintiese insultado, no lo era, sino que era ignorado, algo que le fastidiaba bastante" (Rossanda, 2008, pp. 397-398). El error del movimiento estudiantil fue buscar la alianza con el viejo movimiento obrero, que vegetaba bajo el control de sus partidos y sindicatos, cuando debería aproximarse al "nuevo proletariado, creación específica de la sociedad de capitalismo avanzado, constituido por obreros de elevada formación técnica, amplia cultura y alto nivel de vida", alejado de planteamientos revolucionarios tradicionales pero sensible a "otros más modernos, haciendo con ello posible un campo estratégico revolucionario común para estudiantes y obreros" (Nieto, 1971, pp. 151-154).

En todo caso, ya fuera como jóvenes trabajadores (Touraine, 1968, p. 183), ya como trabajadores jóvenes (Glucksmann, 1976, p. 48 y p. 99), en 1968 un sector de la clase trabajadora comenzó a definirse a partir de claves que lo acercaban a la experiencia de otros jóvenes de clase media y lo alejaban de otros trabajadores de más edad. Escribía Glucksmann: "El joven acampa en la sociedad sin habitarla y la sociedad lo explota sin «integrarlo». [...] Se puede ser joven toda la vida: materialmente esto es la miseria o la inseguridad, burguesamente la maldición e intelectualmente una suerte" (1976, p. 48). Una misma experiencia de exclusión permitió que muchos estudiantes universitarios tomaran conciencia de su "condición proletarizada", no solo en su etapa formativa, sino también como futuros trabajadores (Bensaïd y Weber, 1968, p. 29; Nieto, 1971 , p. 105). Esta toma de conciencia política no era la del intelectual comprometido (engagé) de otros tiempos, individual y atomizada, fundada en el "despertar de una conciencia a las razones de otra clase", dando lugar al "compañero de viaje [...] con su relati- 
va libertad y su irreductible alteridad de testigo exterior". En mayo surgió "un colectivo con conciencia de su estatuto particular y que expresa las necesidades específicas descubiertas en su propia miseria y alienación, y no sentidas por solidaridad con otros desalienados. Sus relaciones con las clases oprimidas por el mecanismo social son, por tanto, objetivas y no afectivas" (Nieto, 1971, p. 104).

Cinco décadas después podemos recuperar la pregunta que Subirós (1989) dejaba en el aire -“mayo del 68: ¿nuestros abuelos o nuestros nietos?"- para proponer, a modo de hipótesis, que aquel fugaz encuentro entre jóvenes universitarios y trabajadores jóvenes, vinculados por la condición precaria, pudiera estar hoy produciéndose de nuevo en la forma de un precariado (Calella, 2013; Standing, 2013) compuesto por individuos que, más allá de sus diferencias, comparten un escenario de relaciones distintas de aquellas que caracterizan al salariado (principal beneficiario de las políticas socialdemócratas de posguerra) y a la vieja clase obrera; individuos precarizados, pero con conciencia de serlo y con voluntad de resistir a esta situación. Standing sitúa la fecha de nacimiento del precariado en el 1 de mayo de 2001, cuando varios miles de personas, mayoritariamente jóvenes estudiantes y activistas sociales, desfilaron en Milán como una protesta alternativa a las manifestaciones sindicales:

Los vetustos sindicalistas [...] no podían sino sentirse perplejos ante aquella nueva masa en movimiento, cuyas reivindicaciones de inmigración libre y una renta básica universal tenían muy poco que ver con el sindicalismo tradicional. Los sindicatos entendían como única respuesta posible a la precarización un regreso al modelo «laborista» que ellos mismos habían contribuido tanto a cimentar a mediados del siglo XX: más empleos estables con seguridad a largo plazo y los arreos complementarios que solían acompañarlo; pero muchos de los jóvenes manifestantes habían visto a la generación de sus padres acomodarse a la pauta fordista de empleos rutinarios a tiempo completo y subordinación a la gestión industrial y a los dictados del capital. Aunque carecían de una agenda alternativa coherente, no mostraban ningún deseo de resucitar aquel laborismo (Standing, 2013, p.18).

¿Expresión renovada de aquel "obrero social [...] procedente de la crisis y reestructuración capitalista, víctima del paro, del trabajo negro, de la explotación generalizada" (Negri, 1980, p. 14)? ¿Retorno del operaismo enfrentado a la institucionalización de la práctica política y sindical de las fuerzas que debían representar a la clase obrera, práctica "que nunca iba más allá de lo posible, procurando no tratar nunca de alcanzar lo imposible?" (Tronti, 2012, p. 112).

\section{¿QUÉ? ACONTECIMIENTO(S) Y REIVINDICACIONES}

"El acontecimiento frustra las previsiones". Con esta frase inicia Lefebvre $(1970$, p. 7) su libro L'irruption (título más adecuado que el escogido para su publicación en castellano: La revolución de hoy). "Al acontecimiento que sacudió la sociedad francesa cada uno trata de darle nombre", abunda Lefort (2009, p. 27). "Lo impensable había advenido" (Baynac, 2016, p. 64), desafiando la confiada estabilidad de un sistema político y económico que parecía inmutable. La narrativa de un mayo "espontáneo" desconoce la existencia de una cultura política radical que en los años anteriores se expresaba en oposición a las guerras de Argelia y Vietnam, pero también en conflictos laborales y estudiantiles (Bensaïd y Weber, 1968, pp. 32-33; Ross, 2008, pp. 34-35). Pero si no espontáneo, sí fue inesperado. Raphaël Glucksmann recuerda el lamento de un activista de las Juventudes Revolucionarias Comunistas en marzo de 1968: "iJoder, nunca va a pasar nada en este país!" (Gluksmann y Glucksmann, 2008, p. 195); y su padre, André, recuerda que unos meses antes un importante periódico vespertino titulaba "Francia se aburre" (Glucksmann, 2007, p. 120).

Los acontecimientos de mayo revelan "una sociedad latente que surge bruscamente" y que había pasado desapercibida a quienes desde "la descripción, el sondeo, las estadísticas y el periodismo", tan solo eran capaces de captar "la sociedad manifiesta" (Glucksmann, 1976, p. 40). Statera (1977, pp. 16-17, p. 21 y p. 32) recuerda cómo las investigaciones sociológicas y psicológicas realizadas en los países que pronto se verían sacudidos por el acontecimiento dibujaban una juventud "fría", "escéptica", sin ninguna inclinación subversiva; de ahí la sorpresa cuando estaIló la protesta. Y plantea la hipótesis de que la misma juventud que se refugiaba en la vida privada en los cincuenta y primeros sesenta es la que sale a las calles y se enfrenta a todas las instituciones en 1968, en ambas circunstancias por las mismas razones: el rechazo al orden social dominante y la aspiración a una vida plena y auténtica.

Glucksmann sostiene que "mayo del 68 pone en crisis los principios de un modo de vivir y de pensar caduco. Lo que hasta ahora se consideraba evidente resulta ser inadecuado" (Glucksmann y Gluscksmann, 2008 , p. 28). Francia vivía con una "memoria falsificada", la de un país y una sociedad unánime y firmemente antifascista, resistente contra el nazismo, olvidadiza de la vergüenza de Vichy. Pues bien: “En 1968, de manera torpe y caricaturesca, la joven Francia saldó cuentas con los eufemismos y con las leyendas con las que la alimentaron" (Glucksmann y Glucksmann, 2008, p. 34). Esta fue, también, radicalizada por su pasado nazi, la situación en Alemania: "La revuelta fue desde el principio un conflicto generacional en torno 
a distintas cuestiones (cómo debía uno trabajar y vivir, cómo concebía uno mismo el mundo, etc.), pero había un asunto particular que en muchas familias degeneraba en auténticos enfrentamientos. «¿Cuánto sabías tú en aquel momento? ¿Qué hiciste?», se les preguntaba sobre todo a los padres que habían combatido en la guerra a sus veinte años" (Mohr, 2008, p. 29). Inglehart (1977, p. 17) considera que este declive en la confianza hacia las instituciones, iniciado en los sesenta, supone una transformación de largo plazo que está anclada en las experiencias formativas de toda una generación, y que esta transmite en cierto modo a las siguientes. "Nuestra protesta estaba precedida por el deterioro de nuestra confianza", resume Kahl (2008, p. 58). ¿Pero hacia dónde, hacia qué instituciones o ámbitos, se dirige esta pérdida radical de confianza?

Marwick (2005) afirma que entre 1958 y 1974 tuvo lugar una revolución cultural que transformó el estilo de vida, las relaciones familiares y las libertades personales de gran parte de la gente corriente, pero de ninguna manera se produjo una revolución política o económica, ni una redistribución fundamental del poder político y económico. ¿Fue mayo solo una "revolución superestructural"? (Statera, 1977, pp. 240-250). Esta es la interpretación dominante del 68, casi desde el momento mismo de los hechos y hasta la actualidad (Granés, 2011). En este sentido, Nieto (1971, p. 158) recuerda la tesis 29 de la llamada carta de la Sorbona: "La revolución burguesa fue jurídica, la revolución proletaria fue económica, la nuestra es una revolución cultural". Por su parte, Bourdieu considera que mayo del 68 fue sobre todo una "gran convulsión del orden simbólico" (2004, p. 79). Sin embargo, Bensaïd (2008, p. 24) considera que "la reducción retrospectiva del movimiento de mayo a la voluntad de liberación antiautoritaria y de modernización de las costumbres ofrece una lectura despolitizada y despolitizante". En este sentido, Cohn-Bendit (1976, pp. 203-205) se fija en Alemania, donde el movimiento ha creado "sus propias estructuras de vida [...] su contra-medio", de manera que decenas de millares de personas viven en comunidades donde se desarrollan nuevas formas de comunicación, relación e intercambio.

Fernández Buey (2009, pp. 64-68) distingue entre dos décadas de los sesenta: la del pop, característica de la contracultura norteamericana, y la de la proletarización, más propia de las vanguardias estudiantiles europeas. Sin embargo, Touraine (1978, pp. 157-158) introduce esta misma distinción en el mayo francés al contrastar Nanterre, más orientada hacia cuestiones políticas y sociales, "revolucionarios más que innovadores culturales", y la Sorbona, con su revuelta cultural "cargada de nuevos planteamientos (más que de reivindicaciones) referidas a la vida personal, la sexualidad, la expresión, que fue el que finalmente preva- leció". Hijos de Marx y de Rimbaud -"hay que transformar el mundo, hay que cambiar la vida" (Fuentes, 2005, p. 49)-, la tensa convivencia entre la "crítica social" y la "crítica artista" (Boltanski y Chiapello, 2002), sin duda la mayor riqueza de 1968, fue también la principal de sus contradicciones. Escribe un protagonista: "mayo quería cambiar la vida y para ello había que salir del capitalismo, lo cual suponía creer en la exaltante posibilidad de hacer la revolución. [...] Mayo del 68 pretendía abolir lo existente y trabajar para su radical mutación" (Ibáñez, 2016, p. 24). Pero la hibridación entre Marx y Rimbaud, o entre Marx y Freud, resultó más sencilla en la teorización freudomarxista y en el grafitismo - “Cuanto más hago el amor, más ganas tengo de hacer la revolución. Cuanto más hago la revolución, más ganas tengo de hacer el amor"-que en la práctica sociopolítica (Harvey, 2005, pp. 39-63).

En 1962 el situacionista Trocchi declaraba: "No estamos interesados en el coup d'etat de Trotsky y Lenin, sino en el coup du monde" (Brown y Anton, 2011, p. 1). Pero ¿cómo, con qué medios, puede llevarse a cabo tal proyecto?

\section{¿CÓMO? MOVIMIENTO E INSTITUCIÓN}

En la entrevista de Sartre a Cohn-Bendit en Le Nouvel Observateur, el filósofo se refiere a la incomprensión generalizada que provoca el hecho de que los activistas "no buscan elaborar un programa, ni dar una estructura al movimiento", que pretendan "destruirlo todo" sin aclarar qué "quieren colocar en lugar de lo que derrumban". "La fuerza de nuestro movimiento -responde Cohn-Bendit- reside precisamente en que se apoya en una espontaneidad «incontrolable», que da el impulso sin pretender canalizar o sacar provecho de la acción que ha desencadenado"; de lo que se trata es de "hacer comprender la situación, no a la totalidad de los estudiantes, ni siquiera a la totalidad de los manifestantes, pero a un gran número de entre ellos", para lo que es preciso "evitar la creación inmediata de una organización o definir un programa que serían inevitablemente paralizantes". Y concluye: "La única oportunidad del movimiento es justamente ese desorden que permite a las gentes hablar libremente y que puede desembocar, por fin, en cierta forma de autoorganización" (L'imagination au pouvoir, une interview de Daniel Cohn-Bendit par Jean-Paul Sartre (1968)).

Si la aspiración a conciliar a Marx y a Freud (o Rimbaud) fue la mejor aportación de 1968 en el terreno de los objetivos, pero también su principal contradicción, en el terreno de la práctica cabe decir lo mismo del intento de conciliar a Marx y a Bakunin (CohnBendit, 1976, p. 130; Glucksmann, 1976, pp. 54-59; Guérin, 1969). Tanto Freud como Bakunin entraron con naturalidad en el pensamiento de mayo a través 
del antiautoritarismo característico del movimiento estudiantil (Nieto, 1971, pp. 241-242). Pero, de nuevo, esta hibridación de marxismo analítico y anarquismo práctico fue mucho más sencilla en la teoría que en la práctica.

En opinión de Ross (2008, p. 154), "no se puede afirmar que el interés por tomar el poder centralizado fuera ajeno a mayo"; por el contrario, Ibáñez (2016, p. 24) sostiene que "mayo del 68 nunca se planteó seriamente la toma del poder", ya que "su inclinación pasaba, más bien, por disolver el poder o por cortocircuitarlo". Un planteamiento menos leninista y más luxemburguista o "situacional". El modelo eran los comités de acción, "figura emblemática de mayo del 68" (Artous, 2008), "vividos como nuevas relaciones sociales" (Ross, 2008, p. 156 y p. 160) y experimentados como "el camino que lleva al individuo aislado hacia la solidaridad y la unidad de la masa proletaria, eliminando con su espontaneidad la característica división de los grupúsculos de izquierda e incluso de los grandes partidos revolucionarios" (Nieto, 1971, p. 244).

La constitución de estos comités de acción (CA), junto a otras prácticas como las ocupaciones (Viénet, 1978) o la puesta en práctica de "estructuras de vida" comunitarias a las que se refería Cohn-Bendit, forman parte de la búsqueda de "lugares soberanos", donde las jerarquías son abolidas, característica de los movimientos del 68 (Glucksmann, 1976, p. 82). El mayo francés se inspira en un formidable "repertorio de confrontación" que se remonta hasta el siglo XVII (TiIly, 1986), entre cuyas acciones destacan la "insurrección urbana" y la "construcción social de la barricada" (Tarrow, 1997, pp. 85-88), que tan familiares resultan en el escenario de 1968. Pero fueron esas otras prácticas de autoorganización las más novedosas y significativas. Su punto débil, la ausencia de coordinación: "Cuanto más fuertes son los CA, más celosos se vuelven de su autonomía, más refractarios a aceptar una línea, más propensos a denunciar la burocracia de cualquier autoridad tutelar. El miedo de recrear una estructura paralizante inhibe a los CA en su conjunto" (Baynac, 2016, p. 281).

Statera sostiene que el impulso original del 68 era primariamente utópico, antes que ideológico, basado en la "agitación creativa", que sustituía el diagnóstico y la estrategia, en la acción directa y la "instantaneidad absoluta", inversión de la relación tradicional entre medios y fines (1977, p. 209 y p. 131). "Nuestra ideología era la espontaneidad absoluta", confirma Cohn-Bendit, y por ello "un movimiento liberador de obligaciones [...] puso de manifiesto la amplitud que éstas adquieren en nuestras sociedades. Todo es posible. La política-ficción está a la orden del día" (1976, p. 134). Frente al "principio de realidad" y "la fuerza normativa de lo fáctico", el poder de la imaginación (Mohr, 2008, p. 30). "En nosotros se despertaba el sentido de la posibilidad. El desarrollo del sentido de la realidad nos interesaba poco", recuerda Kahl (2008, p. 54). "Nosotros habíamos definido un campo de liberación de los apremios: el movimiento estudiantil", reflexiona Cohn-Bendit (1976, p. 132). Liberación incluso del apremio revolucionario por excelencia: el de la consumación de la revolución (Statera, 1977, pp. 219-221). Desde esta perspectiva, representada en el Soyez réaliste, demandez l'impossible, con mayo de 1968 "la revolución entra en la era godeliana de la "incompletitud» y de la "inconsistencia»", abandonando toda idea de lucha final para pensarse como un permanente recomenzar (Glucksmann y Glucksmann, 2008, p. 201).

Baynac recuerda un momento de la manifestación del 8 de mayo cuando, al aproximarse a la Asamblea Nacional, alguien dice "iTomémosla!", recibiendo la siguiente réplica: "iDejemos a esos gilipollas con sus discusiones!". Recordando estos hechos, escribe Baynac: "Aunque este exceso de confianza no carezca de esplendor y desenvoltura, cabría, sin embargo, lamentar el resultado. Ese poder que, en efecto, estaba en la calle, debíamos haberlo utilizado para hacer entrar la calle en la Asamblea. Pero las masas no querían saber nada de un poder que rechazarían sistemáticamente durante todo mayo" (2016, p. 102). Algo similar a lo que plantea Rossanda (2008, p. 400): "Los estudiantes prefirieron que le pouvoir permaneciera indefinidamente en la rue, y ni siquiera tuvieron tiempo para discutir la elección de un eventual líder, en el que por otra parte no delegaban nada. Pero un vacío de poder no dura mucho tiempo. De Gaulle recuperó las riendas".

Ello no obstante, Baynac (2016, p. 118) no deja de valorar esta estrategia dirigida "ocupar y conquistar el tiempo" y no, como en el modelo leninista, a ocupar y conquistar el espacio. Desde su perspectiva, es precisamente en virtud de esta estrategia por lo que verdaderamente puede considerarse que mayo de 1968 es "la revolución de la revolución". Ecos del Glucksmann de entonces: "Haciendo de la calle, de las fábricas y de las universidades los lugares de la vida política, el movimiento nacido en mayo lleva de frente a la repolitización y a la desestabilización, que conducen no a un cambio de programa político sino a un trastorno de la naturaleza misma del poder y, por consiguiente, a una revolución" (1976, p. 37). Los activistas actuaban como si las normas sociales y las mediaciones institucionales se hubiesen suspendido temporalmente, como si no existieran, y seguían autónomamente sus propias normas como si así pudieran prefigurar la sociedad alternativa que imaginaban (Klimke y Scharloth, 2008, p. 5; Ross, 2008, pp. 202-203). "La subversión de la política no se logra más que por la irrupción 
de lo político", en la forma de un sujeto colectivo que irrumpe en la escena pública con el objetivo de gestionar los asuntos sociales de manera directa e igualitaria, defiende igualmente Blanchard pasados los años (2008, p. 130).

Con la referencia de la Comuna y los soviets, el rechazo a que el movimiento revolucionario se organice "en un segundo aparato de Estado" (Glucksmann, 1976, p. 37 y pp. 98-99) predominó en mayo frente a quienes, entonces y ahora, consideran esta ausencia de organización política como causa del relativo fracaso de mayo (Bensaïd, 2008, pp. 25-26; Bensaïd y Weber, 1968, p. 177 y p. 203; Krivine, citado en Statera, 1977, p. 237). Por el contrario, se afirma que fue la pretensión de las distintas facciones marxistasleninistas de "recapturar" ideológicamente una revuelta esencialmente utópica la que provocó que "se consumiera la protesta masiva y se impusiera entre las masas estudiantiles la desilusión y la apatía" (Statera, 1977, pp. 283-284). Como señalara Touraine (1977, p. 225), “era Cohn-Bendit quien tenía razón, y la herencia de mayo del 68 sería muy poco si no fuera más que ese fundamentalismo bolchevique que valerosa e inútilmente intenta recuperar la fuerza inicial del partido leninista".

Ciertamente, la senda bifurcada (Sennett, 2012, pp. 64-71) entre una izquierda política, que sostiene que "para enfrentarse a un gran poder hacía falta otro gran poder" y una izquierda social asociacionista, que considera el acto de cooperar un fin en sí mismo antes que un instrumento estratégico, no surge en los sesenta, pero sí es entonces cuando se consolida, dando lugar a una izquierda libertaria compuesta por jóvenes con formación universitaria, empleados en el sector terciario, con inclinaciones posmaterialistas y rasgos ideológicos heterogéneos -en la medida en que apoyan tanto la autonomía del individuo como los derechos sociales-, que acabará dando la espalda a los partidos y sindicatos de la izquierda clásica (Merkel, 1994, p. 17 y pp. 122-125).

Buscando el difícil equilibrio (uno más) entre utopía e ideología, entre lo político y la política, entre la imaginación y la realidad, Castoriadis señala que el límite de mayo de 1968 fue, sí, la incapacidad para instaurar otras instituciones, pero debían ser unas instituciones esencialmente distintas de las existentes; por ello, la respuesta a este límite no podía ser reducir la acción política a los espacios ya institucionalizados, delimitarla a las instituciones realmente existentes (partidos, elecciones, parlamentos): "[mayo] reveló e hizo visible para todos algo fundamental: el lugar verdadero de la política no es aquel que se creía. El lugar de la política está en todas partes. El lugar de la política es la sociedad" (Castoriadis, 2006, p. 173). Pero el intento de superar el "falso debate" que oponía unilateralmente espontaneidad y organización (Bensaïd y Weber, 1968, pp. 112-113) quedó abierto entonces y continúa en la actualidad, tan vivo o más que en 1968.

El escritor mexicano Carlos Fuentes, por entonces un joven periodista destinado en París, escribe en una de sus crónicas sobre mayo del 68: "Cafés, bistrós, talleres, aulas, fábricas, hogares, las esquinas de los bulevares: París se ha convertido en un gran seminario público. [...] Renació de una manera maravillosa el arte de reunirse con otros para escuchar y hablar y reivindicar la libertad de interrogar y de poner en duda. Los contactos se multiplicaron, se iniciaron, se restablecieron. Hubo una revuelta tan importante como las barricadas estudiantiles o la huelga obrera- contra la calma, el silencio, la satisfacción, la tristeza" (Fuentes, 2005, pp. 25-26). Aquel gran seminario público iniciado en 1968 continúa en la actualidad. El nuevo ciclo de protesta política abierto en España en mayo de 2011 ha llevado a decenas de miles de personas a redescubrir el valor de la conversación democrática; conversación que, prolongada más allá de las plazas en las que surgió, ha dado lugar a un asombroso despliegue de experiencias y prácticas de innovación social aplicadas a multitud de ámbitos de la vida cotidiana.

Se ha dicho que una de las consecuencias más duraderas de los sesenta fue el surgimiento de una sociedad civil mucho menos receptiva a los mensajes de los detentadores del poder estatal y, en consecuencia, el debilitamiento de la capacidad de los Estados para controlar a su ciudadanía (Arrighi, Hopkins y Wallerstein, 1999, p. 90 y p. 96). Pero las preguntas fundamentales de mayo siguen siendo las mismas que hoy desconciertan a los movimientos sociales: ¿cómo sostener la protesta? ¿es posible "cambiar el mundo sin tomar el poder?" (Holloway, 2002); ¿de verdad solo puede haber política realmente libre, emancipatoria, "en la medida en que uno se mantenga a distancia del Estado"? (Badiou, 2008, p. 153). ¿Puede un movimiento antisistémico descuidar la acción política a corto plazo, incluyendo la electoral? (Wallerstein, 2003 , p. 184). Escribe Touraine que su vivencia de dos "situaciones extremas", mayo de 1968 -"el triunfo de la inventiva libertaria"- y el golpe contra Allende en septiembre del 73 -"el hundimiento, tanto económico como político, del socialismo en libertad"- le llevaron a pensar que la contradicción que venimos señalando entre espontaneidad e institucionalización no se resuelve mediante fórmulas tales como la "revolución permanente", sino mediante "otras soluciones más allá de las absolutas, [como] dejar de ignorar la interdependencia de la innovación cultural con los movimientos sociales, la responsabilidad política y la gestión económica” (Touraine, 1977, pp. 13-14). 
¿Tenía razón aquel Cohn-Bendit -el actual rechaza cualquier aproximación "badiouana" a la política (2009, pp. 125-126) - o su espontaneísmo no dejaba de ser una forma de solución "absoluta"? ¿O tenía razón Bensaïd -el de 1968, también el de sus últimos años- empeñado en seguir transitando la "senda estrecha" que, hoy como ayer, se abre a la acción socio- política "entre la «ilusión política», que considera a la democracia de mercado el horizonte infranqueable de una historia exhausta, y la «ilusión social», que pretende impedir que las impurezas del poder dañen a los movimientos de emancipación"? (Bensaïd, 2009, p. 13). La resistencia, la revuelta, la protesta, siguen haciéndose hoy las mismas preguntas.

\section{BIBLIOGRAFÍA}

Arrighi, G., Hopkins, T. K. y Wallerstein, I. (1999). Movimientos antisistémicos. Madrid: Akal.

Artous, A. (2008). Comités de acción. En: Garí, M., Pastor, J. y Romero, M. (eds.). 1968. El mundo pudo cambiar de base. Madrid: Los Libros de la Catarata, pp. 104-111.

Astarian, B. (2008). Las huelgas en Francia durante mayo y junio de 1968. Madrid: Traficantes de Sueños.

Audier, S. (2008). La Pensée anti-68. Paris: La Découverte.

Badiou, A. (2008). Pensar el surgimiento del acontecimiento. Archipiélago, 80-81, pp. 148-160.

Baynac, J. (2016). Mayo del 68: la revolución de la revolución. Madrid: Acuarela y Antonio Machado.

Bell, D. (1976). El advenimiento de la sociedad post-industrial. Madrid: Alianza.

Bensaïd, D. (1998). Sous les pavés, la plage. Sous les pavés, la grève. Viento Sur, 39, pp. 101-105.

Bensaïd, D. (2008). 1968: finales y consecuencias. En: Garí, M., Pastor, J. y Romero, M. (eds.). 1968. El mundo pudo cambiar de base. Madrid: Los Libros de la Catarata, pp. 19-27.

Bensaïd, D. (2009). Elogio de la política profana. Barcelona: Península.

Bensaïd, D. y Weber, H. (1968). Mai 1968: une répetition générale. Paris: François Maspero.

Blanchard, D. (2007). Crisis de palabras. Madrid: Acuarela.

Blanchard, D. (2008). Actualidad de mayo del 68. Archipiélago, 80-81, pp. 121-130.

Blanco, A. (2014). Mitoanálisis del 15M: de la revolución de Prometeo (mayo de 1968) a la red de Hermes (mayo de 2011). Argumentos, 75, pp. 15-34.
Boltanski, L. y Chiapello, E. (2002). El nuevo espíritu del capitalismo. Madrid: Akal.

Bourdieu, P. (2004). Intervenciones 19612001. Ciencia social e intervención política. Hondarribia: Hiru.

Brown, T. y Anton, L. (eds.) (2011). Between the Avant-Garde and the Everyday. New York, Oxford: Berghan Books.

Calella, G. (2013). La fábrica de precarios. En: Fernández, J., Urbán, M. y Sevilla, C. (coords.). De la nueva miseria. La universidad en crisis y la nueva rebelión estudiantil. Madrid: Akal, pp. 103-121.

Castoriadis, C. (1998). El ascenso de la insignificancia. Madrid: Cátedra.

Castoriadis, C. (2006). Una sociedad a la deriva. Entrevistas y debates (1974-1997). Buenos Aires: Katz.

Chollet, L. (2007). La révolte en images. Mai 1968. Paris: Éditions Hors Collection.

Clifford, R., Gildea, R. y Warring, A. (2013). Gender and sexuality. En: Gildea, R., Mak, J. y Warring, A. (eds.). Europe's 1968. Oxford: Oxford University Press, pp. 239-257. https://doi.org/10.1093/ acprof:oso/9780199587513.003.0010

Cohn-Bendit, D. (1976). El gran bazar. Barcelona: Dopesa.

Cohn-Bendit, D. (2009). Forget 68. La Tour d'Aigues: Éditions de l'Aube.

Cohn-Bendit, D. (2010). ¿Qué hacer? Barcelona: RBA.

Cohn-Bendit, D. y Dammann, R. (eds.) (2008). La rebelión del 68. Barcelona: Global Rhythm Press.

Coutrot, T. (2012). La sociedad civil, cal asalto del capital? En Agamben, G., Rancière, J., Badiou, A., Neyrat, F. Jappe, A., Žižek, S. et al. Pensar desde la izquierda. Mapa del pensamiento crítico para un tiempo en crisis. Madrid: Errata Naturae, pp. 117-130.

Delporte, Ch. (2007). 68 en héritage médiatique. MédiaMorphoses, 4, pp. 195-202.
Duverger, M. (2008). La rebelión de la juventud. La Factoría, 11 (35), pp. 17-22.

Elbaum, M. (2002). What Legacy from the Radical Internationalism of 1968 ? Radical History Review, 82, pp. 37-64. https://doi.org/10.1215/016365452002-82-37

Evans, S. M. (2015). Women's Liberation: Seeing the Revolution Clearly. Feminist Studies, 41 (1), pp. 138-149. https://doi. org/10.15767/feministstudies.41.1.138

Fernández Buey, F. (2009). Por una universidad democrática. Madrid: El Viejo Topo.

Feuer, L. S. (1971). El cuestionamiento estudiantil del establishment en los países capitalistas y socialistas. Buenos Aires: Paidós.

Finkielkraut, A. (2001). La ingratitud. Barcelona: Anagrama.

Finkielkraut, A. (2014). La identidad desdichada. Madrid: Alianza.

Fuentes, C. (2005). Los 68. París, Praga, México. Barcelona: Debate.

Gallant, M. (2008). Los sucesos de mayo. París, 1968. Barcelona: Alba.

Gallant, T. W. (2009). «Got a Revolution, got to revolution»: Student Activism and the Antiwar Movement. An Historical Assessment. Historein, 9, pp. 57-66. https://doi.org/10.12681/historein.22

Garí, M., Pastor, J. y Romero, M. (eds.) (2008). 1968. El mundo pudo cambiar de base. Madrid: Los Libros de la Catarata.

Gil Villa, F. (2014). Los estudiantes y la democracia. Madrid: Plaza y Valdés.

Gilcher-Holtey, I. (2008). France. En: Klimke, M. y Scharloth, J. (eds.). 1968 in Europe. A History of Protest and Activism, 1956-1977. New York: Palgrave Macmillan, pp. 111-124. https://doi. org/10.1057/9780230611900_10

Gitlin, T. (1987). The Sixties. Years of Hope, Years of Rage. New York: Bantam Books. 
Glucksmann, A. (1976). Hacia la subversión del trabajo intelectual. México: Era.

Glucksmann, A. (2007). Una rabieta infantil. Madrid: Taurus.

Glucksmann, A. y Glucksmann, R. (2008) Mayo del 68. Por la subversión permanente. Madrid: Taurus.

Gómez Pin, V., Romero, P. G., Eraso, S., Gómez, J. J., Fernández-Savater, A., Garre, A., Candón, J. I., Escudero, I., Benlloch, M. y Oviedo, S. (2012). Política Poética. De mayo del 68 al 15-M. Sevilla: Fundación Pública Andaluza Centro de Estudios Andaluces

Granés, C. (2011). El puño invisible. Madrid Taurus.

Gretton, J. (1969). Students and Work ers. An analytical account of dissent in France, May-June 1968. London: McDonald.

Guérin, D. (1969). Pour un marxisme libertaire. Paris: Robert Laffont.

Hampden-Turner, Ch. (1978). El hombre radical. Proceso del desarrollo psicosocial. Madrid: Fondo de Cultura Económica.

Harvey, D. (2005). A Brief History of Neoliberalism. Oxford, New York: Oxford University Press.

Hermann, K. (1968). Los estudiantes en rebeldía. Madrid: Rialp.

Holloway, J. (2002). Cambiar el mundo sin tomar el poder. Madrid: El Viejo Topo.

Ibáñez, T. (2016). Deseo de mayo. En: Baynac, J. Mayo del 68: la revolución de la revolución. Madrid: Acuarela y Antonio Machado, pp. 13-25.

Inglehart, R. (1971). The Silent Revolution in Europe: Intergenerational Change in Post-Industrial Societies. The American Political Science Review, 65 (4), pp. 991 1071. https://doi.org/10.2307/1953494

Inglehart, R. (1977). The Silent Revolution. Princeton: Princeton University Press.

Kahl, R. (2008). Cafés y manifestaciones. En: Cohn-Bendit, D. y Dammann, R. (eds.). La rebelión del 68. Barcelona: Global Rhythm Press, pp. 53-86.

Keucheyan, R. (2013). Hemisferio izquierda. Madrid: Siglo XXI.

Klimke, M. y Scharloth, J. (eds.) (2008). 1968 in Europe. New York: Palgrave Macmillan. https://doi. org/10.1057/9780230611900
La Parra-Pérez, P. (2014). Revueltas lógicas: el ciclo de movilización del $15 \mathrm{M}$ y la práctica de la democracia radical. Journal of Spanish Cultural Studies, 15 (1-2), pp. 39-57. https://doi.org/10.1080/146 36204.2014.938457

Leblanc, A. (2009). L'iconographique de Mai 68 : un usage intentionnel du photoreportage en noir et blanc ou couleur. L'exemple de Paris-Match (maijuin 1968). Sens Public, 2.

Lefebvre, H. (1970). La revolución de hoy. México: Editorial Extemporáneos.

Lefort, C. (2009). El nuevo desorden. En: Morin, E., Lefort, C. y Castoriadis, C., Mayo del 68: la brecha. Buenos Aires: Nueva Visión, pp. 27-47.

L'imagination au pouvoir, une interview de Daniel Cohn-Bendit par Jean-Paul Sartre (1968). [En línea]. Disponible en https:// www.nouvelobs.com/politique/lecongres-du-ps/20081023.OBS7477/Iimagination-au-pouvoir-une-interviewde-daniel-cohn-bendit-par-jean-paulsartre-1968.html

Luce, P. A. (1966). La nueva izquierda. Barcelona: Dima Ediciones.

Mannheim, K. (1993). El problema de las generaciones. Revista Española de Investigaciones Sociológicas, 62, pp. 193242. https://doi.org/10.2307/40183643

Martin, J.-Ph. (2014). Les contestations paysannes autour de 1968. Des luttes novatrices mais isolées. Histoire \& Sociétés Rurales, 41, pp. 89-136.

Marwick, A. (2005). The Cultural Revolution of the Long Sixties: Voices of Reaction, Protest, and Permeation. The International History Review, 27 (4), pp. 780806. https://doi.org/10.1080/0707533 2.2005 .9641080

Merkel, W. (ed.) (1994). Entre la modernidad y el postmaterialismo. La socialdemocracia europea a finales del siglo XX. Madrid: Alianza.

Miguel, A. de (1979). Los narcisos. El radicalismo cultural de los jóvenes. Barcelona: Kairós.

Mohr, R. (2008). El amor a la revolución. En: Cohn-Bendit, D. y Dammann, R. (eds.). La rebelión del 68. Barcelona: Global Rhythm Press, pp. 23-52.

Morin, E. (2009). La comuna estudiantil. En Morin, E., Lefort, C. y Castoriadis, C. Mayo del 68: la brecha. Buenos Aires: Nueva Visión, pp. 9-25.
Negri, T. (1980). Del obrero-masa al obrero social. Barcelona: Anagrama.

Nieto, A. (1971). La ideología revolucionaria de los estudiantes europeos. BarceIona: Ariel.

Premat, Ch. (2009). Mai 68, le conflit des interpretations. Sens Public, 2.

Pudal, B. y Retière, J.-N. (2008). Les grèves ouvrières de 68 , un mouvement social sans lendemain mémoriel. En: Damamme, D., Gobille, B. y Matonti, F. (dirs.). Mai-Juin 68. Paris: Les Éditions de l'Atelier/ Les Éditions Ouvrière, pp. 207-221.

Rome, A. (2003). "Give Earth a Chance»: The Environmental Movement and the Sixties. The Journal of American History, 90 (2), pp. 525-554. https://doi. org/10.2307/3659443

Ross, K. (2008). Mayo del 68 y sus vidas posteriores. Madrid: Acuarela y Antonio Machado.

Rossanda, R. (2008). La muchacha del siglo pasado. Madrid: Foca.

Roszak, T. (1970). El nacimiento de una contracultura. Barcelona: Kairós.

Roth, J. (2004). La filial del infierno en la Tierra. Escritos desde la emigración. BarceIona: Acantilado.

Ruiz Fernández, J. (2016). Agustín García Calvo en el 15-M. Las Torres de Lucca. International Journal of Political Philosophy, 5 (8), pp. 247-279.

Sander, H. (2008). Carta a Sani. En: CohnBendit, D. y Dammann, R. (eds.). La rebelión del 68. Barcelona: Global Rhythm Press, pp. 87-120.

Sauvy, A. (1971). La rebelión de los jóvenes. Barcelona: Dopesa.

Scott, M. B. y Lyman, S. M. (1970). The Revolt of the Students. Columbus: Charles E. Merrill Publishing Company.

Sedlmaier, R. A., Sedlmaier, A. y Malinowski, S. (2011). '1968'. A Catalyst of Consumer Society. Cultural and Social History, 8 (2), pp. 255-274. https://doi.org/ 10.2752/147800411X12949180694461

Sennett, R. (2012). Juntos. Rituales, placeres y política de cooperación. Barcelona: Anagrama.

Sorman, G. (2011, 23 de octubre). El movimiento de los indignados se parece a lo que ocurrió en mayo del 68. El Mundo.

Standing, G. (2013). El precariado. Una nueva clase social. Barcelona: Pasado y Presente. 
Statera, G. (1977). Muerte de una utopía. Madrid: Felmar.

Strain, Ch. B. (2016). The Long Sixties. America, 1955-1973. Chichester, Hoboken: John Wiley \& Sons.

Subirats, J. (2011, 22 de octubre). El Moviment del $15-\mathrm{M}$, com va passar amb el Maig del 68, representa un canvi d'època. El Triangle.

Subirós, P. (1989). Mayo del 68: ¿nuestros abuelos o nuestros nietos? El Viejo Topo, Extra 11, pp. 4-5.

Tarrow, S. (1997). El poder en movimiento. Madrid: Alianza.

Tilly, Ch. (1986). The Contentious French Cambridge, Mass.: The Belknap Press of Harvard University Press. https://doi. org/10.4159/harvard.9780674433984
Today the big political game is 'bashing the 1960s'. Interview with Daniel Cohn-Bendit. En: Farik, N. (ed.) (2008). 1968 revisited. 40 years of protest movements. Brussels: Heinrich Boll Foundation, pp. 63-67.

Touraine, A. (1968). Le comunisme utopique. Paris: Seuil.

Touraine, A. (1973). La sociedad post-industrial. Barcelona: Ariel.

Touraine, A. (1977). Cartas a una estudiante. Barcelona: Kairós.

Touraine, A. (1978). Un deseo de historia. Autobiografía intelectual. Madrid: Zero.

Townson, N. (2011, 6 de junio). El 15-M: ¿un nuevo mayo de 1968? El País.

Tronti, M. (2012). Nuestro operaismo. New Left Review, 73, pp. 103-120.
Vallespín, F. (2009). De la rebelión al consumo. Foreing Policy Edición española, 26, pp. 28-32.

Viénet, R. (1978). Enragés y situacionistas en el movimiento de las ocupaciones. Madrid: Castellote.

VV. AA. (1976). Textos de la nueva izquierda (Selección, traducción e introducción de Andrés Linares). Madrid: Castellote.

Wallerstein, I. (2003). ¿Qué significa hoy ser un movimiento anti-sistémico? $O b$ servatorio Social de América Latina, 9, pp. 179-184.Da coruntias molut parum venimuscipsa cullabo. It el min ex eum alis sit landitatio ommodipita nobis estia velestempore sinus peri ilit illecae pudandae sectorest, cuptata ectiatum vera nonsecabore venietur moloratume 